\title{
Body Painting: Corpos cenográficos
}

\author{
Mona Magalhães \\ Universidade Federal do Estado do Rio de Janeiro - Unirio - Rio de Janeiro - Brasil \\ E-mail: mona.magalhaes@unirio.br
}

\section{Resumo}

Este artigo foi apresentado na $P Q$ talks - mesa Expanding Scenography durante a $14^{\text {a }}$ Prague Quadrennial of Performance Design and Space - PQ2019. Trata-se da body painting como linguagem artística com potencial para produzir interferência urbana, na qual os corpos podem se camuflar, fundindo-se com o ambiente em que vivem, ou destacando-se do espaço da cidade e do ambiente social, provocando efeitos extracotidianos em ações puramente performativas. Assim, temos um plano de expressão que se articula com um plano de conteúdo, materializado em enunciados pintados no corpo de um sujeito historicamente localizado em um espaço e tempo definidos, compondo, portanto, conforme Patrice Pavis (1999, p. 232), um "cenário de ambulante", capaz de ser um "elemento estético totalizante da encenação". A pintura corporal é dotada de um plano de expressão visual, no qual cores, formas, topologia e matéria se fundem, no suporte corporal, para criar códigos socialmente interpretáveis pelo hábito ou para produzir sentidos inesperados. Existe uma correspondência entre conteúdos que oscilam em relação ao plano de expressão, produzindo desde os sentidos usuais até os surpreendentes. Como um "cenário ambulante", o corpo sob a pintura pode ser recuado ou visível, deformado ou invertido, em um espaço e tempo operados na dimensão do ato discursivo, isto é, aqui e agora. Assim, declarações pintadas podem definir o corpo como um contraponto e / ou uma reiteração em relação à cidade (Espaço / aqui). A sensação ou ilusão de ótica de um corpo ausente nas pinturas corporais libera, portanto, esse corpo dos sentidos sociais enraizados culturalmente sob a pele, deixando-o livre para provocar novos sentidos e criar outros espaços.
This article was presented at $P Q$ talks - Expanding Scenography Panel during the 14th Prague Quadrennial of Performance Design and Space - PQ2019. It addresses body painting as an artistic language capable of producing urban interference in which bodies can be camouflaged either merging with the environment in which they are, or standing out in the urban environment, yielding extra-everyday effects in purely performative actions. We therefore have the articulation of an expression plane and a content plane, materialized in body paintings on historically located subjects in a specific space and time frame, thus composing, according to Patrice Pavis (1999, p. 232), a "moving scenery", capable of being a "totalizing aesthetic element of the staging". Body painting is endowed with a visual expression plane in which colors, shapes, topology and matter merge in the body support so as to create codes socially interpretable by habit, or produce unexpected senses. There is a correspondence between contents that fluctuate in relation to the expression plane, producing senses that range from the usual to the surprising. As a "moving scenery", the body under the painting can be drawn back or visible, deformed or inverted, in a space and time operated in the dimension of the discursive act, that is, here and now. Thus, painted statements can define the body as a counterpoint and / or a reiteration of its relation to the city (Space / here). The optical sensation or illusion of an absent body in body paintings frees that body from social senses culturally rooted under the skin, leaving it free to provoke new senses and create other spaces. 
Este trabalho foi apresentado na série de discussões e palestras da PQ Talks da Prague Quadrennial of Performance Design and Space - PQ2019. Na PQ talks, sob a curadoria de Pavel Drábek (CZ)

e Barbora Príhod (CZ), apresentaram-se artistas internacionais, renomados e iniciantes, oriundos de várias disciplinas voltadas para a área do design da cena. Nas sessões, foram analisadas as tendências contemporâneas da cenografia, além de reflexões críticas sobre a colaboração artística no teatro, incluindo técnicas, processos e fontes de inovação. "Expanding Scenography" (Cenografia em expansão) foi o tema da mesa da qual participaram os seguintes artistas pesquisadores: Tanja Beer (AU), cuja comunicação tratava da "Introduction to Ecoscenography" (Introdução a Ecocenografia); Renato Bolelli Rebouças (BR), que falou sobre a "Poetics of Destruction: between the spectacle and its rubble - Scenography expanded, Globalization and Performance" (Poética da destruição: entre o espetáculo e seus escombros - Cenografia expandida, Globalização e Performan$\mathrm{ce})$; Eric Villanueva Dela Cruz (PH), que representou o grupo composto por ele, Lawyn Cruz (PH), Tuxqs Rutaquio $(\mathrm{PH})$ e Magda De Leon $(\mathrm{PH})$ abordando a "Extending Audience Engagement Through Taste" (Ampliando o engajamento do público através do gosto); e, ainda, esta autora, que apresentou o trabalho de título homônimo, que segue mais detalhado.

Começo a partir da concepção contemporânea de arte, na qual a cenografia arrisca novas formas de pensar o espaço da intervenção artística. Sigo pela resposta de Tali Itizhaki à pergunta de Pamela Howard (2015, p. 31), no seu livro O que é cenografia?. "Em essência: um ser humano em um espaço humano." Continuo ainda com outras respostas dadas a Howard: A cenografia hoje é "a mudança constante de percepção do corpo, do espaço, do tempo e do significado" (HUSSEIN, 2015, p. 20), que "considera as diversas maneiras pelas quais o espaço cênico gera significados" (IRWIN, 2015, p. 19) que articulam o espaço e a "informação visual em artes temporárias" (SCHMIDT, 2015, p. 23), numa "polifonia - não uma ordem hierárquica - de elementos teatrais distintos"
(GOEBBELS, 2015, p. 20), gerando uma "poética visual do espetáculo" (PANTOUVAKI, 2015, p. 20).

Dentre as informações visuais das artes temporárias, destaco a maquiagem (MAGALHÃES, 2010), uma das linguagens artísticas que compõem a caracterização visual de um personagem num espetáculo teatral. O embelezamento, a acentuação de traços, a codificação do rosto, a teatralização da fisionomia e a extensão para o corpo são as funções da maquiagem, de acordo com o pensamento de Patrice Pavis (1999, p. 231). Destaco, neste artigo, apenas a função de estender a maquiagem para o corpo, denominada de Body painting. Cabe observar que a bodypainting é considerada uma arte em ascensão, paradoxalmente a mais antiga e, ao mesmo tempo, contemporânea forma de arte. Ela é dotada de plano de expressão visual, em que categorias cromáticas, eidéticas, topológicas e matéricas se mesclam para, sobre o suporte corporal, criar códigos socialmente interpretáveis pelo hábito ou produzir sentidos inesperados. A bodypainting corresponderá a conteúdos que oscilarão, em articulação com o plano da expressão, entre a habitualidade e a surpresa. As "finas membranas" (id., 2003, p. 170) que se ajustam sobre a pele, móveis e efemeramente coloridas, podem provocar nos observadores atração ou repulsa, sensualidade ou susto, choque ou cumplicidade.

É uma linguagem artística com potencial para produzir interferências ${ }^{1}$ urbanas, nas quais, por meio dela, os corpos podem se camuflar, fundindo-se com o ambiente em que se encontram, ou destacar-se do espaço da cidade e do ambiente social, provocando efeitos extracotidianos em ações puramente performativas. Assim, temos um plano de expressão que se articula com um plano de conteúdo, materializado

1 A opção pelo termo Interferência foi feita a partir do pensamento do artista Ronald Duarte que, numa entrevista a Kenny Neoob Castro (2010, p. 5), destacou a diferença entre intervenção e interferência. Para ele "intervenção é uma maneira de inventar intervindo, reinventando alguma coisa na cidade; reinventar o urbano, dialogar com o espaço". E "interferência tem a intenção de transgredir, de cortar, de fracionar, de ser a transversalidade da cidade, não tem nada com a invenção do espaço". 
em enunciados pintados no corpo de um sujeito historicamente localizado em espaço e tempo definidos, compondo, portanto, conforme explica Patrice Pavis, um "cenário ambulante", capaz de ser um "elemento estético total da encenação" (id., 1999, p. 232). Como um "cenário ambulante", o corpo sob a pintura pode estar recuado ou visível, deformado ou invertido, em um espaço e tempo operados na dimensão do ato discursivo, isto é, no aqui e agora da apresentação.

As reflexões sobre a pintura corporal e o espaço (urbano, natural ou cênico) são oriundas da pesquisa institucional $\mathrm{O}$ corpo e a cidade: pesquisa sobre bodypainting, de conteúdo teórico e prático, desenvolvida desde 2011 na Escola de Teatro da Universidade Federal do Estado do Rio de Janeiro - Unirio - Brasil. A proposta inicial da pesquisa é verificar o corpo em relação à cidade por meio da bodypainting. As pinturas podem colocar o corpo como contraponto e/ou reiteração em relação aos espaços urbanos, construídos pelo ser humano, ou aos espaços do mundo natural, tornando-os cênicos.

\section{O corpo que interessa}

Cabe aqui ponderar sobre o corpo que interessa neste contexto. Trata-se do corpo humano como suporte sensível da arte, que oferece sua superfície já repleta de sentidos, para que, por meio da pintura, este pareça distorcido, retorcido, recuado, revirado para quebrar o senso comum do cotidiano. O corpo que irradia as relações sociais e consolida o sensível e as diferentes relações com o mundo que o cerca, conforme explica o semioticista francês Jacques Fontanille (2004, p. 12). O corpo como "vetor semântico" da relação que é construída com o mundo, tornando-a evidente e perceptível. É pelo corpo que o ser humano se apropria da sua existência no mundo e a traduz para os outros, por meio dos sistemas simbólicos compartilhados para a comunidade.

O corpo fenomenológico que é visível e reflexivo, característico de um indivíduo com suas peculiaridades físicas, psíquicas e sociais, fruto das interrogações que Merleau-Ponty $(1989,2006)$ fez à Ciência e à Filosofia. O corpo concreto e sensível, exposto a forças e tensões, internas e externas. $O$ corpo que é sujeito e objeto da arte, um "sincretismo de sujeito e objeto" (TATIT, 1996, p. 201), cuja manifestação figurativa mais frequente desse estado indiferenciado - ou mesmo invertido - das funções é a do sujeito tornando-se objeto das emoções produzidas pelo objeto estético (ibid.). O corpo que é objeto numa cena, mas que é também sujeito da ação capaz de chamar o foco para si e para o espaço onde está inserido. O corpo que como sujeito observa o que acontece ao seu redor e o incorpora no momento em que ele é objeto em cena e decide o que deve ser visto. Enfim, o corpo sensível, que vê e é visto, transformado em objeto de cena, mas que é capaz de sensibilizar a si mesmo e ao outro. Do mesmo modo como o sociólogo Henri-Pierre Jeudy explica, ou seja, "o corpo, como objeto entre outros, é também sujeito, com o ato de ver implicando que a corporeidade das coisas se impõe a ele no momento mesmo em que - como objeto - ele crê decidir por uma boa parte do que está vendo" (JEUDY, 2002, p. 150).

A este corpo (sensível, fenomenológico, sincrético) agregam-se as funções de espaço e de lugar. Como espaço, recorro às dimensões do plano de expressão plásticas/visuais (topológica, cromática, eidética e matérica) e às propriedades de base do envelope corporal (conexão, compactação e interface de triagem) estabelecidas pela semiótica de origem francesa. Para melhor compreensão, vale esclarecer esses conceitos. A semiótica plástica é constituída pelos formantes pictóricos que, de acordo com Oliveira (2004, p. 119), estão na descrição de uma pintura, "possuem uma natureza composta por certas dimensões": as cores constituem a dimensão cromática e a forma compõe a dimensão eidética. É a partir das matérias, dos materiais, das técnicas e dos procedimentos que essas duas dimensões irão se organizar e ganhar uma corporeidade "que, quando é apreendida por sua fisicalidade própria, constitui por si mesma uma dimensão distinta das demais, a matérica" (ibid.). A combinação dessas três dimensões concretiza a dimensão topológica, que é a distribuição e a 
ocupação espacial em um suporte. Já as propriedades de base do corpo, ou melhor, do envelope corporal, são definidas por Fontanille (2004, p. 150) como: conexão -- um todo único e contínuo; compactação o corpo sólido, denso, sem espaços vazios; interface de triagem - que regulariza e polariza os intercâmbios entre o que é próprio e não próprio ao sujeito, ou o que é próprio e não próprio ao meio social de referência. Desse modo essa propriedade funciona como uma separação entre próprio e não próprio.

\section{Corpos entre espaço e lugar}

Para entender o espaço, recorro ao pensamento de Michel de Certeau (2008), que o entende como a prática do lugar. Assim, como lugar, o corpo serve como ponto de observação no espaço urbano e/ou natural ao qual está inserido no momento da pintura. O corpo é, assim, o lugar de onde o sujeito senciente (MERLEAU-PONTY, 1989) sente o mundo. Temos então um corpo como espaço topológico, conexo e compacto. O corpo espaço topológico é onde serão organizadas as cores e as formas a serem aplicadas sobre ele. Estas preservarão ou destruirão a conexão e/ou a compactação do corpo para dar a ilusão de torção, de distorção ou de recuo no determinado espaço urbano/natural que deve ser destacado.

Sobre os espaços urbanos, destaco os que são gerados e limitados pelos elementos arquitetônicos. É neles que se manifestam diferentes dimensões da forma arquitetônica (visual, tátil, auditiva, odorífica) que só serão percebidas pelo cidadão caso ele se demore nos lugares. É notório que esses espaços visíveis correm o risco de se tornar invisíveis diante do excesso e da "banalização das imagens do mundo" (BUORO, 2013, p. 881). Do mesmo modo, uma paisagem natural, muitas vezes, no vai e vem do cotidiano, também se torna invisível "sob uma chuva ininterrupta de imagens", como observa Italo Calvino (1990, p. 73) em Seis propostas para o novo milênio. Ou ainda pelo olhar da sociossemiótica, nas palavras de Landowski.
Imagens ou edifícios, objetos manufaturados, obras de arte ou figuras do mundo natural, as coisas estão aqui, visíveis. Visíveis, reconhecíveis, nomeáveis, e ao mesmo tempo indiferentes ou, no limite, pior ainda, pesadas e entediantes: peças de museus, "maravilhas" arqueológicas pelas quais o olhar vagueia, mas que nada nos dizem; catedrais, paisagens e castelos massivamente colocados diante de nós e, enquanto tais, impenetráveis - paralisantes. Lembranças da infância e de domingos! De forma tal que, diante disso tudo, o sujeito se desejaria presente de outro modo: pressentimento, para além do visível, não de algo invisível, mas de um suportável que restituiria sentido a todas essas coisas e lhes daria presença diversa.

(LANDOWSKI, 2004, p. 97, grifo do autor).

Portanto, se o modo do sujeito se inserir no mundo é por meio da linguagem, da comunicação e das caminhadas que faz pela cidade, de acordo com as teorias de Certeau (op.cit.), pergunto o que faz o sujeito criar espaços perceptíveis ou recuperar o que se perde com o hábito do cotidiano. Todos os objetos, edifícios, obras de arte, paisagens etc. são visíveis, reconhecíveis, nomeáveis, mas, com o passar do tempo, tornam-se pesadas e entediantes e começam a não dizer mais nada por serem impenetráveis, acabam perdendo o sentido. Como fazer para recuperar o que se perde com o hábito do cotidiano e tornar os espaços invisíveis novamente perceptíveis?

É preciso deixar de caminhar sem perceber e sem comunicar por causa da cegueira e da pressa da rotina e do habitual ou pelo excesso visual. Devese arrancar a venda; às vezes, é preciso mudar o rumo, "girar o corpo e ver o que não tinha visto antes" (TEIXEIRA, 2004, p. 221). Mas o que nos impulsiona a mudar a direção da caminhada para encontrar ou reencontrar espaços e percebê-los, ou, ainda, dar novos sentidos a eles? O modo do sujeito se inserir no mundo é por meio da linguagem, da comunicação. Se o corpo é o lugar de onde vemos o mundo, é pelo olhar que expandimos o espaço. Retomo as reflexões de Teixeira (ibid, p. 201) a propósito da leitura de Images à la sauvette, de Cartier-Bresson (1952), de que o "espaço começa a 
partir do nosso olho e se expande ao infinito, depois de nos tocar com mais ou menos intensidade, para se fechar em nossas lembranças e aí se modificar". Nada melhor que o próprio corpo, do cidadão, do suporte sensível, que se torna sujeito e objeto artístico coberto por cores efêmeras para que os outros caminhantes freiem o passo, girem o corpo e recuperem o olhar contemplativo de um espaço refeito, ressignificado. A pele, invólucro do corpo humano, é a fronteira entre o corpo e a cidade, que separa e coloca em comunicação o sujeito e o mundo.

Os usos físicos do homem dependem de um conjunto de sistemas simbólicos. Do corpo nascem e se propagam as significações que fundamentam a existência individual e coletiva; ele é o eixo da relação com o mundo, o lugar e o tempo nos quais a existência toma forma através da fisionomia singular de um ator. Através do corpo, o homem apropria-se da substância, traduzindo-a para os outros, servindo-se dos sistemas simbólicos que compartilha com os membros da comunidade. O ator abraça fisicamente o mundo, apoderando-se dele, humanizando-o e, sobretudo, transformando-o em universo familiar, compreensível e carregado de sentidos e de valores que, enquanto experiência, podem ser compartilhados pelos atores inseridos, como ele, no mesmo sistema de referências culturais. Existir significa em primeiro lugar mover-se em determinado espaço e tempo, transformar o meio graças à soma de gestos eficazes, escolher e atribuir significado e valor aos inúmeros estímulos do meio graças às atividades perceptivas, comunicar aos outros a palavra, assim como um repertório de gestos e mímicas, um conjunto de rituais corporais implicando a adesão dos outros. Pela corporeidade, o homem faz do mundo a extensão de sua experiência, transformando-o em tramas familiares e coerentes, disponíveis à ação e permeáveis à compreensão. Emissor ou receptor, o corpo produz sentidos continuamente e assim insere o homem, de forma ativa, no interior de dado espaço social e cultural. (LE BRETON, 2006, p. 7).

\section{Bodypainting: inscrições efêmeras para expansão de espaços}

Um dos meios de reforçar ou alterar os sentidos em um espaço urbano e/ou natural, ou, ainda, do próprio corpo, é a bodypainting. Esta faz da pele uma superfície de inscrições temporárias, capaz de transformar as propriedades corporais, deformando-as, invertendo-as e até mesmo recuando-as, para provocar vertigens ao produzirem efeitos de sentidos estéticos inusitados. A sensação ou ilusão de ótica de um corpo ausente nas pinturas artísticas libera o sujeito dos sentidos sociais culturalmente arraigados sobre a pele, deixando-o livre para provocar outros sentidos e expandir os espaços.

Utilizo aqui o pensamento dos professores Cássio Hissa e Maria Luísa Magalhães Nogueira (2013, p. 61), segundo os quais "o corpo sente, pensa e diz a cidade e, ao dizê-la, transforma-se nela". Assim, digo que é por meio da pintura corporal contemporânea que o corpo sente, pensa e mostra a cidade, mesclando-se e/ou opondo-se a ela, transformando-se visualmente nela. Continuo com Hissa, Nogueira (ibid.) e incluo Santos, para quem o corpo, sem dúvida, é "uma certeza materialmente sensível, diante de um universo difícil de compreender" (SANTOS, 2008, p. 314).

Como objeto estético e gerador de sentido, a bodypainting, como texto visual, coloca em competição o corpo e a pintura (duas grandezas e dois modos de existência), conforme explica Fontanille (2007), nos quais uma forma ascende e a outra descende, possibilitando as transformações como revoluções, distorções, remanejamentos ou flutuações nas ilusões que levam o observador a perder de vista o suporte sensível sob a pintura, visualizá-los ao mesmo tempo ou, ainda, rever o que foi visto em outra obra artística.

É a atração, o susto, o choque que faz com que o transeunte freie o passo, gire o corpo, perceba ou reveja espaços e se ausente de si para "assistir de dentro à fissura do ser" (TEIXEIRA, op.cit.). Ao ser tocado pela obra, fissura-se; ao "ser fissurado, pensa e, na reflexão, reencontra a unidade, refaz a experiência,

Magalhães // Body Painting: Corpos cenográficos Revista Cena, Porto Alegre, $n^{\circ}$ 31, p. 41-53 mai./ago. 2020

Disponível em: http://seer.ufrgs.br/cena 
atribuindo-Ihe sentido" e capacidade de se apropriar e recriar novos lugares no espaço urbano da cidade.

Ubersfeld (2005, p. 117) esclarece que "o espaço teatral não é vazio: ele é ocupado por uma série de elementos concretos cuja importância relativa é variável. São eles: os corpos dos atores, os elementos do cenário, os acessórios. A presença muda ou a imobilidade de um corpo humano pode ser significante como a presença de um outro objeto". Assim, quando falamos de tornar o espaço urbano ou natural em um espaço cênico para que o cidadão transeunte possa tornar a percebê-lo, o corpo humano, ainda mais recoberto por camadas de maquiagem, é de vital importância. O espaço tornado cênico por meio da bodypainting permitirá ler a poética da imagem e a relação com o contexto (histórico, político, social). O espaço (urbano ou natural) agora cênico passa a ser, como explica Ubersfeld (ibid.), "lugar da conjunção do simbólico e do imaginário, do simbolismo comum a todos, e do imaginário próprio de cada um". Ao se defrontar com um corpo transformado pela pintura, o transeunte pode ser atraído ou se assustar, fazendo-o frear o passo, girar o corpo, perceber ou rever espaços urbanos ou naturais para ressignificá-los. De fato, o que acontece aqui é a transposição de um espaço urbano/natural em espaço cênico, um acontecimento no meio de todo o excesso cotidiano.

\section{Bodypaintings como performance e interferências urbanas}

No projeto O Corpo e a Cidade: pesquisa sobre bodypainting foram realizadas quatro interferências urbanas desenvolvidas a partir dos pensamentos abordados anteriormente. A duas primeiras aconteceram em 2016 no espaço urbano construído no período de 1936 a 1945 sob a responsabilidade de Lúcio Costa, ao qual se juntaram talentos precoces: Oscar Niemeyer, Affonso Redy, Carlos Leão, Jorge Machado Moreira, Ernani Vasconcellos e também o paisagista Burle Marx, inspirados e avalizados pelo arquiteto suíço Le Corbusier. Foi o próprio então ministro da Educação e Saúde, Gustavo Capanema, quem escolheu os arquitetos e o renomado pintor Candido Portinari para criar os diversos painéis e murais que comporiam a futura sede do Ministério da Educação, o Palácio Capanema. E foi um dos diversos murais de azulejos criados por Portinari que serviu como base para as interferências urbanas Motivos Marinhos: Envolturas Corporais no Capanema (MAGALHÃES, 2017) (Figura 1) e Por Ti Mariana: Portinari Sobre $\mathrm{Pele}^{2}$. As razões que nos levaram a realizar essas interferências foram: a extinção do Ministério da Cultura pelo então Presidente Michel Temer (2016); e o rompimento da barragem da mineradora Samarco no município de Bento Ribeiro, distrito da cidade de Mariana (2015), Minas Gerais. Foram ações em tempo real, com duração de doze horas, em um espaço público, sede da Funarte (Fundação Nacional das Artes), do Iphan (Instituto do Patrimônio Histórico e Artístico Nacional) e de setores administrativos do Ministério da Cultura. Os cinco corpos dos atores Gabriel José, Lívia Bravo, Lucas Drigues, Julia Bravo e Tainá Lasmar puderam ocupar as paredes do Palácio Capanema, na cidade do Rio de Janeiro, durante a ocupação do edifício pelos artistas (OcupaMinc) que reivindicavam o retorno do Ministério da Cultura. Foi uma espécie de reconquista de um espaço público, referência da arte brasileira, uma ocupação de fato: os murais de Portinari mesclados aos corpos dos artistas órfãos. Foi criado um trompe-l'oeil, no qual os conflitos políticos foram expressos por meio da alteração cromática dos elementos marinhos, para, em seguida, serem cobertos por lama.

O processo destas interferências foi curto, toda a produção foi levantada em uma semana. O desejo de realizar uma bodypainting nesse espaço era antigo; a oportunidade, urgente e única. Uma visita para

2 Equipe: Coordenadora: Mona Magalhães. Atores e pintores: Gabriel José (monitor voluntário), Julia Bravo (monitora), Lívia Bravo (monitora voluntária), Lucas Drigues (Bolsista de Integração Acadêmica - BIA), Tainá Lasmar (PIBIC - CNPQ), Vitor Martinez (voluntário). Produtores voluntários: Ravi Arrabal, Júlio Freitas. Fotógrafo voluntário: Eitô Muniz. Técnicas utilizadas: pincel, esponja e estêncil. Materiais: aquacolor e lama. 
escolher o local apropriado, registrar os corpos em uma formação expressiva, copiar as figuras marinhas para posterior produção dos estênceis, comprar as aquacolors. Ao contrário do processo, o dia da interferência foi longo, doze horas de muito trabalho, expectativas, aprendizado e emoções. Ouvir o espanto dos que acompanharam a jornada ao verem os corpos fundirem-se ao mural de Portinari. A confirmação da potência do corpo humano que, de fato, chamou atenção para aquele espaço tão significativo para a arte em um momento frágil para a cultura brasileira.

\section{Figura 1 - Motivos Marinhos: envelopes corporais} no Capanema.

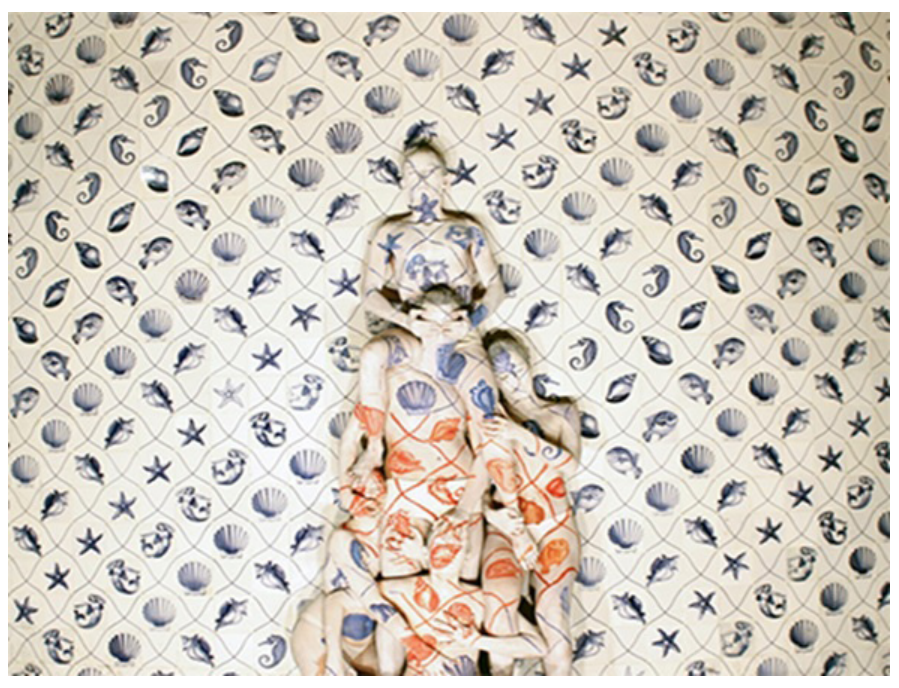

Fonte: arquivo pessoal. Fotografia: Eitô Muniz.

Na terceira interferência urbana foi proposto um remanejamento semiótico, no qual as figuras do quadro Picasso pintadas sobre corpos se relacionaram à Praça Marechal Floriano, mais conhecida como Cinelândia, no centro da cidade do Rio de Janeiro, Brasil. Guernica Bodypainting (MAGALHÃES, 2018), realizada em 03 de dezembro de 2017, envolveu cerca de 30 artistas entre corpos modelos, pintores e fotógrafos. Os elementos que compõem o quadro de Guernica: o touro, o cavalo, o pássaro, a portadora da lamparina, a mão do guerreiro segurando a espada quebrada e uma flor, a mãe com o filho morto nos braços, o homem caído, a mulher do incêndio, a muIher perdida e a luminária/sol, foram representados por dezoito corpos masculinos e femininos pintados e posicionados na escadaria da Câmara Municipal do Rio de Janeiro, representando o momento político, social e econômico que vivia, e ainda vive, o Brasil, especialmente a Cidade e o Estado do Rio de Janeiro. É importante destacar como informação histórica que a praça Cinelândia, onde está situada a Câmara Municipal do Rio de Janeiro, foi e é palco de manifestações populares, culturais, de comícios políticos e, nos últimos tempos, esses acontecimentos vêm acompanhados de tumultos, de brigas, de confrontos com a polícia, de balas de borracha e de bombas de gás lacrimogênio. Diferente das interferências anteriores, o processo desta foi longo.

Durante dois semestres os corpos foram preparados para conseguirem resistência. Nesse mesmo período, exploram-se as composições corporais e os traços (Figura 2) que melhor retratassem as formas das figuras de Picasso. Incluem-se ainda visitas à Cinelândia e à Câmara dos Vereadores, para pesquisar o espaço e a busca de um ponto de apoio para a realização das pinturas no dia da interferência. Chegado o dia, aportamos na Esdi (Escola Superior de Desenho Industrial - UERJ), nosso ponto de apoio, onde ficamos por cerca de oito horas, para o processo da pintura. Rumamos para as escadarias da Câmara Municipal em cortejo e, no percurso, atraímos olhares e seguidores curiosos. Do mesmo modo que nas interferências anteriores, entre rumores, tivemos retorno imediato do público que observava as figuras tomarem forma. Novamente, fizemos corpos pararem e girarem para admirar 
Guernica Bodypainting ${ }^{3}$ (Figura 3) e reverem o edifício onde se abriga o Poder Legislativo municipal.

\section{Figura 2 - Processo de execução de} Guernica Bodypainting.

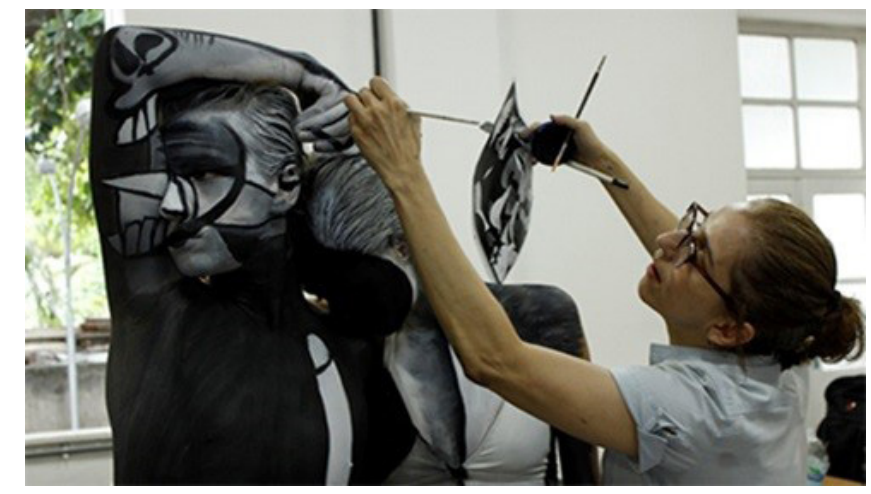

Fonte: arquivo pessoal. Fotografia: Eitô Muniz

Figura 3 - Detalhe de Guernica Bodypainting.

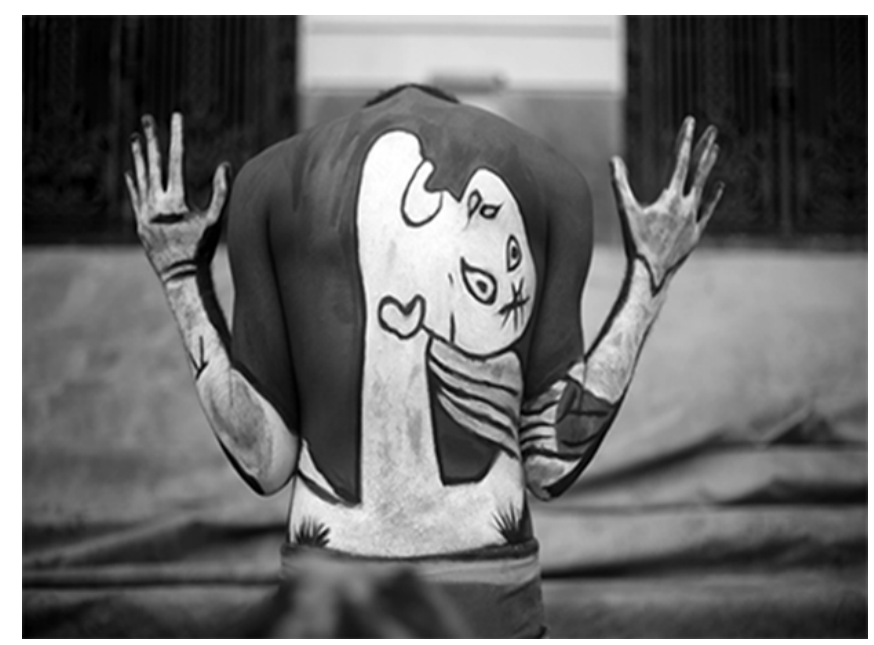

Fonte: arquivo pessoal. Fotografia: Eitô Muniz.

3 Equipe: Coordenadora: Mona Magalhães. Vice-coordenador: Carlos Alberto Nunes. Pintores: Mona MagaIhães, Adriana Dehoul (voluntária), Gabriel José (Bolsista de Integração Acadêmica - BIA), Julia Bravo (bolsista de extensão), Leonardo Tonon (voluntário), Lívia Bravo (monitora), Lucas de Oliveira (PIBIC - CNPQ), Rodrigo Reinoso (voluntário), Tainá Lasmar (PIBIC - CNPQ) e Vitor Martinez (voluntário). Atores: Ana Bessa, Arthur Cardoso, Barbara Cristina, Dandara Costa, Erika Dark, Farley Matos, João Pedro, Léa Nogueira, Lilian Marinho, Lucas Marinho, Mariana Cassimiro, Ricardo Aguilar, Talita Dantas, Tayson Pio. Voluntários: Bruna Novaes (CAL), Felipe de Barros (CAL), Júlio Freitas, Ravi Arrabal. Fotógrafos: Eitô Muniz, Eduardo Maya e Mauro Marques. Costureiras: Katia Salles, Regina Oliva. Técnicas utilizadas: pincel, esponja, moldes. Material: Aquacolor.
A quarta interferência urbana, na verdade, se faz na forma de séries intituladas $O$ importante é $O$ que interessa ${ }^{4}$, realizadas ao longo do ano de 2019, em reação à declaração da ministra da Mulher, da Família e dos Direitos Humanos do governo Jair Bolsonaro, Damares Regina Alves: "menino veste azul, menina veste rosa". A partir dessa afirmação, perguntamos: o que de fato importa para construção e promoção do bem-estar numa sociedade? O espetáculo de rua Les gens de couler, do grupo francês llotopie, nos serviu de inspiração. Os corpos coloridos expressariam a liberdade de sermos o que somos, com a responsabilidade de respeitar e conhecer o outro. Diferente do grupo francês, a interação entre os corpos, objetos, edifícios e espaços devia ocorrer entre cores distintas, no intuito de ampliar o universo das relações e conhecimento mútuo. Os corpos humanos cobertos por cores vibrantes, ao se inserirem

\section{Equipe série 1}

Coordenadora: Mona Magalhães. Vice-coordenador: Carlos Alberto Nunes. Pintores: Flávia Lopes, Mona Magalhães, Silvia Moiella e Vitor Martinez. Atores: Igor Bernardo Y'panema, Caroline Lima, Regina Mascarenhas, Amanda Tedesco, Emanuel Risant, Marina Mota, Rebeca Queiroz, Irene Milhomens, Fernanda Klayn. Fotógrafo: Eitô Muniz. Apoio: Biblioteca Central e Setor de Transporte da Unirio. Técnica utilizada: pincel. Material: Aquacolor.

\section{Equipe série 2}

Coordenadora: Mona Magalhães. Vice-coordenador: Carlos Alberto Nunes. Pintores: Bruna Casagrande (Monitora), Fellipe Estevão (Bolsista de extensão), Lucas de Oliveira (PIBIC - CNPQ), Mariane Cassimiro (IC - Unirio), Mona Magalhães, Ricardo Aguilar (Bolsista de Integração Acadêmica), Silvana Rocio (Monitora voluntária), Tainá Lasmar. Atores: Aline Sampin, Anderson Caetano, Bernardo Scofano, Bruno Marques, Caetano Dable, Caroline Lima, Dandara Costa, Fernanda Klayn, Flora Lis, Juliana Thiré, Monique Alves, Natacha Almeida, Pedro Lopes, Thauane Oliveira, Rebeca Queiroz. Fotógrafos: Cecília Vaz e Ricardo Aguilar.

\section{Equipe série 3}

Coordenadora: Mona Magalhães. Vice-coordenador: Carlos Alberto Nunes. Pintores: Fellipe Estevão (Bolsista de extensão), Lucas de Oliveira (PIBIC - CNPQ), Mona Magalhães, Ricardo Aguilar (Bolsista de Integração Acadêmica) e Everton Cherpinsk. Atores: Catharine Bon, Dan Tavares, Dandara Costa, Erika Bernardo, Perola Mattos e Yhorana Carpanelli. Fotógrafos: Caetano Dable e Lia Ximenes. 
no espaço urbano/natural, ressaltam a importância e as funções dos lugares, reativando memórias e chamando a atenção dos transeuntes. O que foi percebido nessas interferências é que, ao caminharmos pelas ruas, a identificação entre as cores acontece pelos próprios transeuntes. São eles que se aproximam das cores que os identificam. Por exemplo: o vendedor de mate na praia, que usa um colete amarelo, veio interagir com a atriz que estava coberta pela mesma cor. O mesmo aconteceu com os garis da Comlurb (Companhia Municipal de Limpeza Urbana) (Figura 11), de uniforme laranja, que se aproximaram imediatamente do ator coberto pela cor do uniforme.

O processo destas séries de interferências se diferencia das outras três por ser monocromática e, portanto, de mais simples aplicação. Contudo, não menos atrativa. A relação do tema com os espaços foi planejada, mas as ações realizadas pelos corpos coloridos eram improvisadas. As cores intensas ressaltam a beleza do corpo humano cuja conexão é preservada, ou seja, as formas humanas são percebidas como tal. E talvez por isso mesmo sejam arrebatadoras. Nas três primeiras séries temos: Educação ( $\mathrm{Fi}-$ gura 4), Liberdade (Figura 5), Transporte (Figura 6), Saúde (Figura 7), Alimentação (Figura 8), Habitação (Figura 9), Futuro (Figura 10), Limpeza urbana (Figura 11), Justiça (Figura 12) e Censura não (Figura 13).

Figura 4 - O Importante é o que interessa Série 1 - Educação.

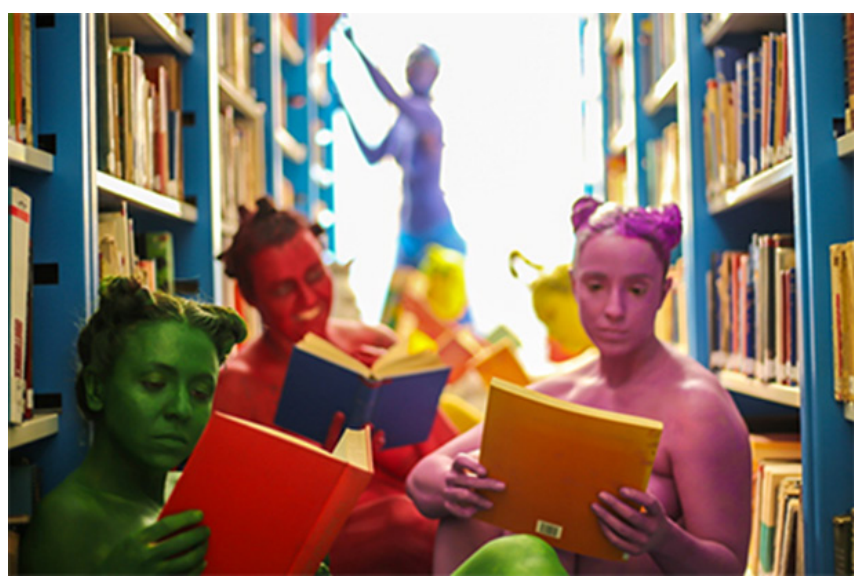

Fonte: arquivo pessoal. Fotografia: Eitô Muniz.
Figura 5 - O Importante é o que interessa Série 1 - Liberdade.

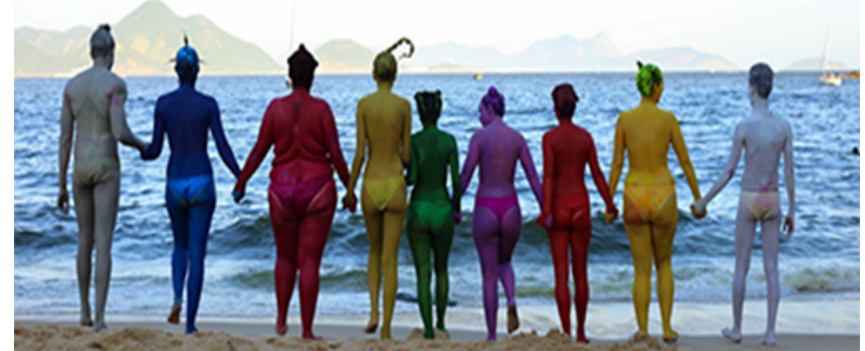

Fonte: arquivo pessoal. Fotografia: Eitô Muniz.

Figura 6 - O Importante é o que interessa Série 1 - Transporte.

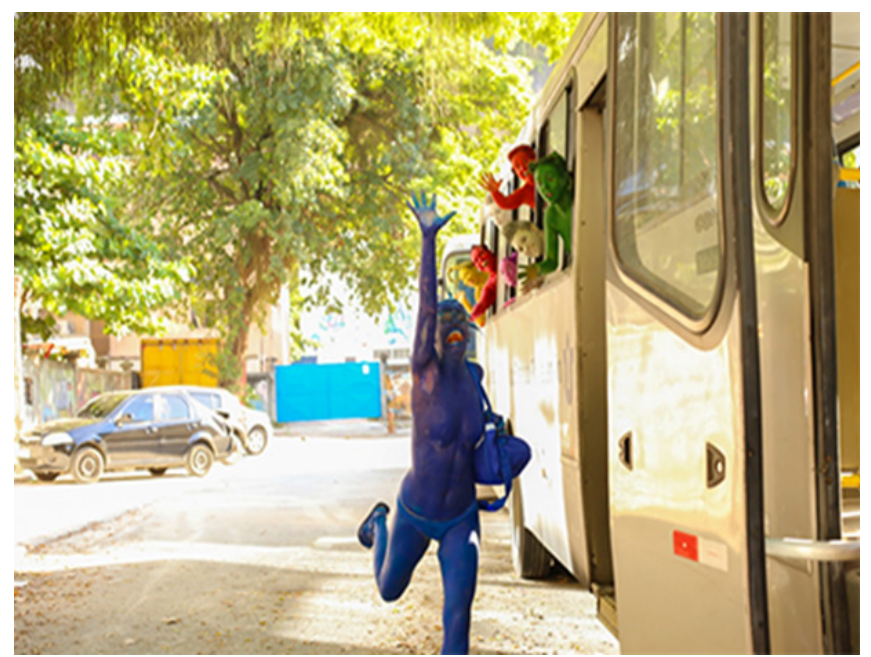

Fonte: arquivo pessoal. Fotografia: Eitô Muniz. 
Figura 7 - O Importante é o que interessa Série 2 - Saúde.

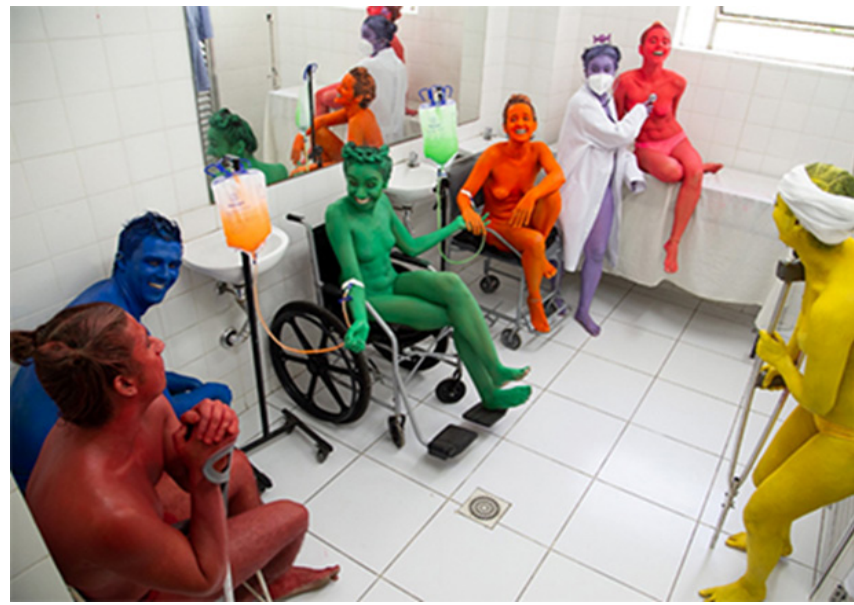

Fonte: arquivo pessoal. Fotografia: Cecília Vaz.

Figura 8 - O Importante é o que interessa Série 2 - Alimentação.

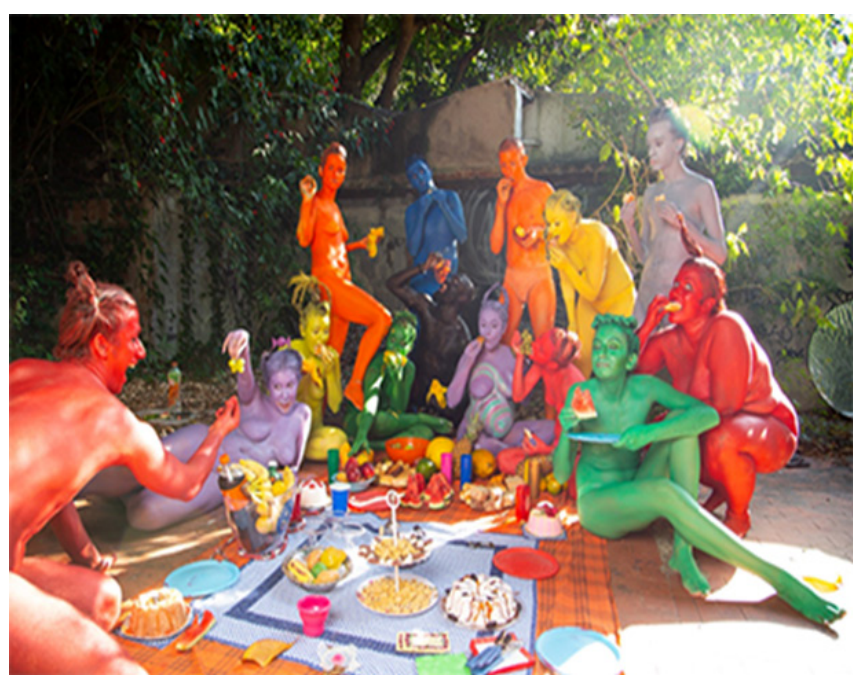

Fonte: arquivo pessoal. Fotografia: Cecília Vaz.
Figura 9 - O Importante é o que interessa Série 2 - Habitação.

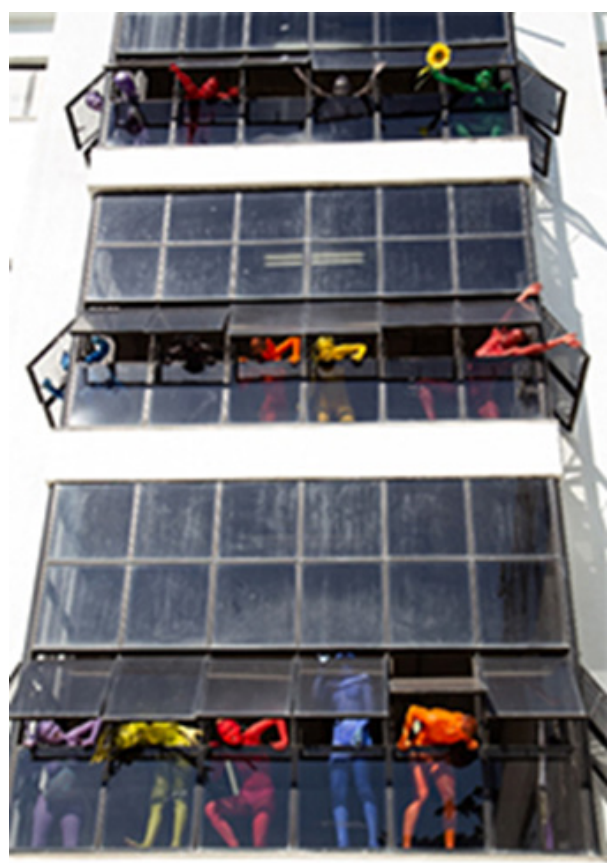

Fonte: arquivo pessoal. Fotografia: Cecília Vaz.

Figura 10 - O Importante é o que interessa Série 2 - Futuro.

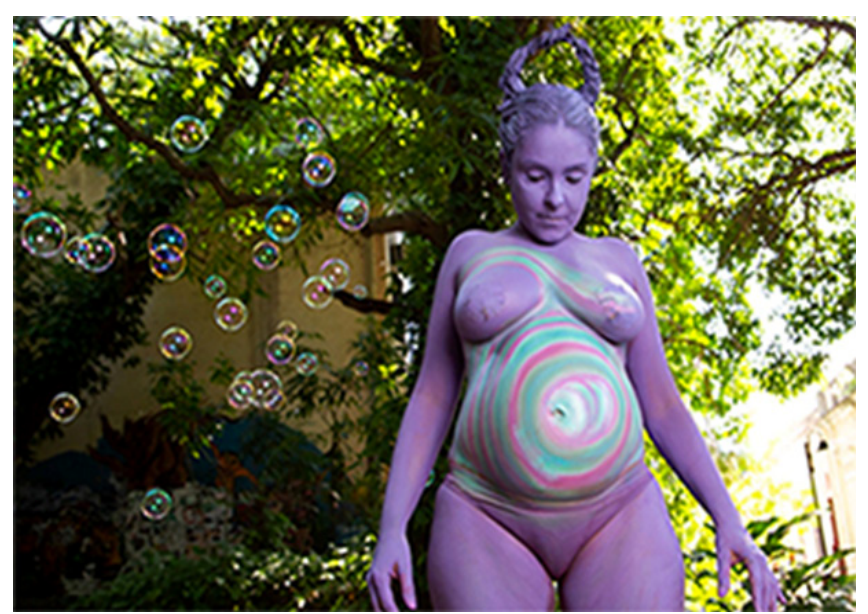

Fonte: arquivo pessoal. Fotografia: Cecília Vaz. 
Figura 11 - O Importante é o que interessa Série 2 - Limpeza Urbana.

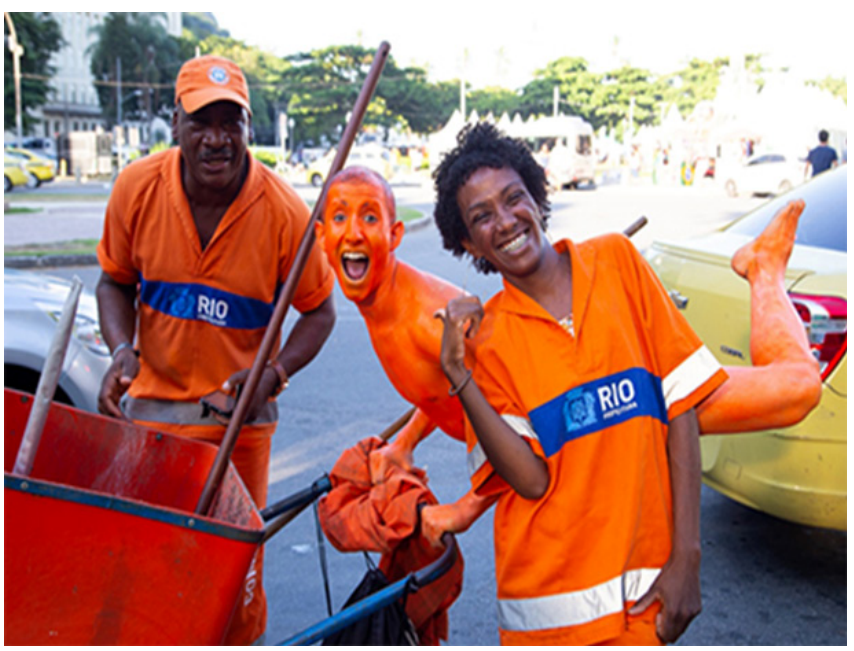

Fonte: arquivo pessoal. Fotografia: Cecília Vaz.

Figura 12 - O Importante é o que interessa Série 3 - Justiça.

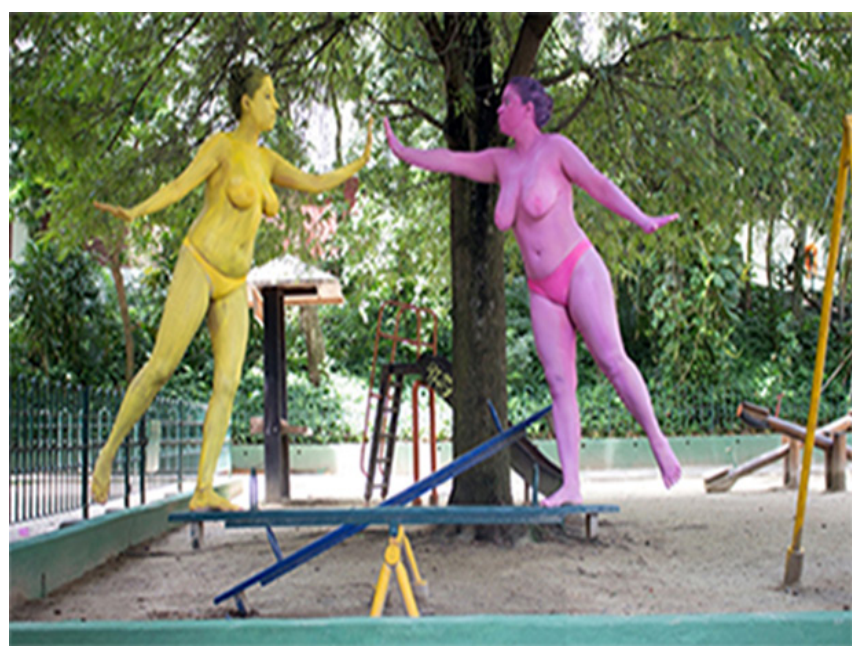

Fonte: arquivo pessoal. Fotografia: Lia Ximenes.
Figura 13 - O Importante é o que interessa Série 3 - Censura não.

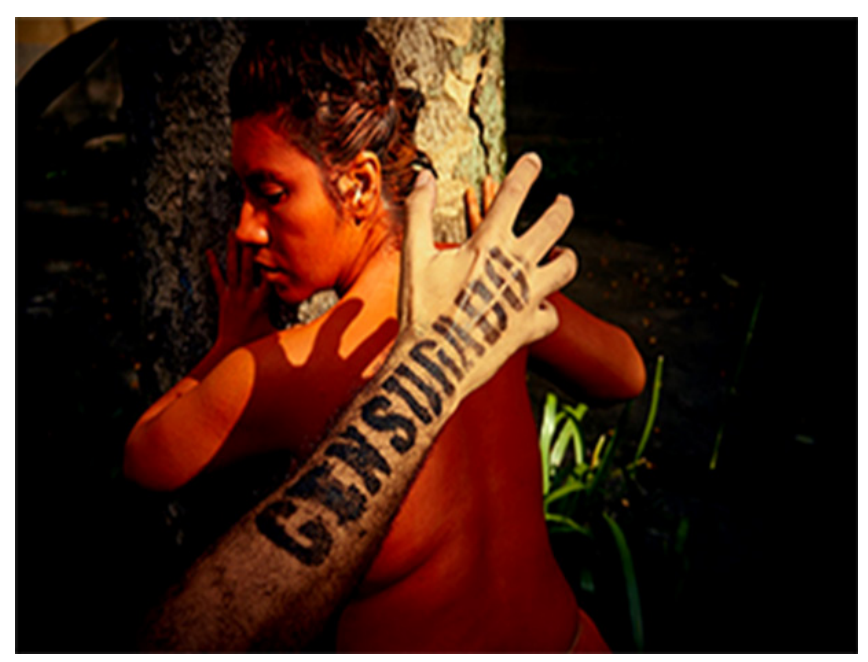

Fonte: arquivo pessoal. Fotografia: Caetano Dable.

\section{Pensamento para finalizar}

Participar desta mesa na PQ talks representa uma abertura para as pesquisas sobre a maquiagem cênica e artística que, normalmente, enfrentam dificuldades de encontrar e de promover discussões e reflexões que ultrapassem as apresentações técnicas. Ao expandir seu campo, a cenografia apresenta diversos caminhos nos quais a maquiagem e a bodypainting podem também ganhar amplitude como linguagem artística e performática.

Este foi meu segundo contato com a Prague Quadrennial of Performance Design and Space, sendo o primeiro, na edição de 2015 , apenas como visitante. Nessas duas edições, percebi que ainda há um espaço limitado para a maquiagem. Em 2015, destaco o trabalho da Dinamarca, na Exhibiting Countries and Regions (Mostra dos Países e Regiões), que apresentou o trabalho "Through Different Eyes" (Através de Outros Olhos), produzido pela Global Stories Theatre Company (Companhia Teatral Global Stories), a partir das experiências do ator Nielsen Morten. O intuito era provocar a reflexão sobre os conceitos de maioria, minoria, etnia e discriminação. Para isso, a produção proporcionava aos visitantes a possibilidade de trocar de aparência, de etnia, de gênero ou de idade por meio de maquiagens, peru- 
cas e figurinos. Na edição de 2019 não houve um estande em que a maquiagem e/ou bodypainting preponderassem. Elas apareceram em performances, em algumas mostras de países, em conjunto, porém, com as outras linguagens visuais e sonoras.

Assim, os quinze minutos destinados à apresentação na mesa "Expanding Scenography" (Cenografia em expansão), no dia 15 de junho de 2019, foram um marco para a pesquisa sobre a maquiagem cênica e a bodypainting, por serem os únicos destinados a esse tema. Apesar de ser o último dia das $P Q$ talks, a plateia estava cheia e atenta; alguns participantes manifestaram sobre a beleza do corpo humano ressaltada pelas cores e pelo espaço urbano. Além do mais, o corpo humano, como suporte e/ou na exacerbação dos seus sentidos, também foi elemento central nas outras comunicações apresentadas.

De fato, a bodypainting se insere na concepção contemporânea de arte que - tal qual a cenografia - atenta para a mudança constante de percepção do corpo, do espaço, do tempo e do significado. Aventura-se assim em novos caminhos de pensar o espaço artístico de interferências para a construção de uma poética visual que coloca o ser humano num espaço humano.

\section{Referências}

BUORO, Anamelia Bueno. O turista e o museu: encontros possíveis. In: OLIVEIRA, Ana Claudia de. As interações sensíveis: ensaios de sociossemiótica a partir da obra de Eric Landowski. São Paulo: Estação das Letras e Cores, 2013.

CALVINO, Italo. Seis propostas para o próximo milênio. São Paulo: Companhia das Letras, 1990.

CASTRO, K. N. C.; DUARTE, R.; Alexandre Vogler; FERRAZ, G.; Luis Andrade. Intervenções urbanas?. Revista Polêmica, v. 7, p. 5, 2007.

CERTEAU, Michel de. A invenção do cotidiano: artes de fazer. Petrópolis: Vozes, 2008.
FONTANILLE, Jaques. Soma et Séma: figures du corps. Paris: Maisonneuve \& Larose, 2004.

Semiótica do Discurso. São Paulo: Contexto, 2007.

GOEBBELS, Heiner. In: HOWARD, Pamela. O que é cenografia? São Paulo: Edições SESC, 2015.

HISSA, Cássio E. Viana; NOGUEIRA, Maria Luísa Magalhães. Cidade-Corpo. Revista UFMG, v. 20, n.1, p.54-77, jan./jun. 2013.

HUSSEIN, Nesreen. In: HOWARD, Pamela. O que é cenografia? São Paulo: Edições SESC, 2015.

HOWARD, Pamela. O que é cenografia? São Paulo: Edições SESC, 2015.

IRWIN, Kathleen. In: HOWARD, Pamela. O que é cenografia? São Paulo: Edições SESC, 2015.

JEUDY, Henri-Pierre. O corpo como objeto de arte. São Paulo: Estação Liberdade, 2002.

LANDOWSKI, Eric. Modos de presença do visível. In: OLIVEIRA, Ana Claudia de. (Org.). Semiótica Plástica, São Paulo: CPS-Hacker editores, 2004.

LE BRETON, David. A sociologia do corpo. Petrópolis: Editora Vozes, 2006.

MAGALHÃES, Mônica Ferreira. Maquiagem e pintura corporal: uma análise semiótica. 2010. Tese (Doutorado em Estudos Linguísticos). Instituto de Letra, Universidade Federal Fluminense. Niterói, 2010. 
Motivos Marinhos: envolturas corporais no Capanema E Por Ti Mariana: Portinari sobre pele processos das intervenções espaciais no Palácio Gustavo Capanema. In: Memória ABRACE XVI - Anais do IX Congresso da Associação Brasileira de Pesquisa e Pós-Graduação em Artes Cênicas. Anais...Uberlândia (MG) UFU, 2017. Disponível em: < http://https//www.even3.com.br/anais/IXCongressoABRACE/32147-Motivos-Marinhos--Envolturas-Corporais-No-Capanema-E-Por-Ti-Mariana--Portinari-Sobre-Pele---Processos-Das-Interven >. Acesso em: 14 mai. 2019.

Guernica Bodypainting: entre performance, artes integradas e intervenção urbana. In: Anais do Simpósio Reflexões Cênicas Contemporâneas. Campinas, Unicamp, 2018. Disponível em: < https:// www.cocen.unicamp.br/revistadigital/index.php/simposiorfc/article/view/604 >. Acesso em 14 mai. 2019.

MERLEAU-PONTY, Maurice. O filósofo e sua sombra. In: CHAUÍ, Marilena. Textos Selecionados. São Paulo: Nova Cultural, 1989.

Fenomenologia da Percepção. SãoPaulo: Martins Fontes, 2006.

OLIVEIRA, Ana Claudia de. As semioses pictóricas. In: OLIVEIRA, Ana Claudia de (Org.). Semiótica Plástica. São Paulo: Hacker, 2004, p. 115-158.

PANTOUVAKI, Sofia. In: HOWARD, Pamela. O que é cenografia? São Paulo: Edições SESC, 2015.

PAVIS, Patrice. Dicionário de teatro. São Paulo: Perspectiva, 1999.

A análise dos espetáculos. São Paulo: Perspectiva, 2003.
PRAGUE QUADRENNIAL 2019. Catalogue 2019. Disponível em: < http://www.pq.cz/wp-content/ uploads/2020/03/PQ19-catalogue-web.pdf >. Acesso em 30 jan. 2020.

PRAGUE QUADRENNIAL 2019. PQ Talks. Disponível em: < https://www.pq.cz/2018/03/27/pq-talks-3/ >. Acesso em: 30 jan. 2020.

SANTOS, Milton. A natureza do espaço: técnica e tempo, razão e emoção. São Paulo: HUCITEC, 2008.

SCHMIDT, Bob. In: HOWARD, Pamela. O que é cenografia? São Paulo: Edições SESC, 2015.

TATIT, Luiz. Corpo na semiótica e nas artes. In: SILVA, Inacio Assis. Corpo e sentido: a escuta do sensível. São Paulo: Editora da Universidade Estadual Paulista, 1996. p. 195-209.

TEIXEIRA, Lucia. Station Bourse: o que os olhos não viram. In: CORTINA, Arnaldo; MARCHEZAN, Renata Coelho (Orgs.). Razões e sensibilidades: a semiótica em foco. Araraquara: Laboratório Editorial/ FCL/UNESP. São Paulo: Cultura Acadêmica, 2004, p.221-247.

UBERSFELD, Anne. Para ler o teatro. São Paulo: Perspectiva, 2005.

Recebido: 05/03/2020

Aprovado: 10/06/2020 